\title{
Treating liver fat and serum triglyceride levels in NAFLD, effects of PNPLA3 and TM6SF2 genotypes: results from the WELCOME* trial
}

Authors: Eleonora Scorletti ${ }^{1,2}$, Annette L West ${ }^{1}$, Lokpal Bhatia ${ }^{1,2}$, Samuel P Hoile ${ }^{1}$, Keith G McCormick $^{1,2}$, Graham C Burdge ${ }^{1}$, Karen A Lillycrop ${ }^{1}$, Geraldine F Clough ${ }^{1}$, Philip C Calder ${ }^{1,2}$, Christopher D Byrne ${ }^{1,2}$

${ }^{1}$ Human Development and Health Academic Unit, Faculty of Medicine, University of Southampton, Southampton, UK (ES, ALW, LB, SPH, KGM, GCB, KAL, GFC, PCC, CDB)

${ }^{2}$ National Institute for Health Research Southampton Biomedical Research Centre, University Hospital Southampton NHS Foundation Trust and University of Southampton, Southampton, UK (ES, LB, KGM, PCC, CDB)

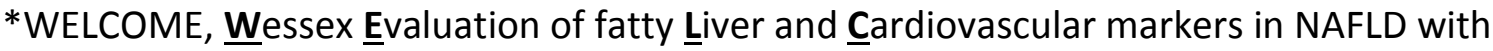
OMacor thErapy.

Key words: Omega-3 fatty acid, DHA, docosahexaenoic acid; EPA, eicosapentaenoic acid; PNPLA3, patatin-like phospholipase domain-containing protein-3; TG, triglyceride; NAFLD, non alcoholic fatty liver disease; liver fat; WELCOME, Wessex Evaluation of fatty Liver and Cardiovascular markers in NAFLD with OMacor thErapy.

Corresponding author: Eleonora Scorletti, Human Development and Health Academic Unit, Faculty of Medicine, University of Southampton, Institute of Developmental Science (IDS) Building, MP887 University of Southampton, Southampton General Hospital, Tremona Road, Southampton SO16 6YD, UK. Email: e.scorletti@soton.ac.uk; Telephone: +4407739388474; Fax number: +44(0) 2381204221 .

Funding: This work was supported by the National Institute of Health Research (NIHR) through the NIHR Southampton Biomedical Research Unit in Nutrition (and Lifestyle), by Diabetes UK, and by the Parnell Diabetes Trust.

All authors declare that: 1) the paper is not under consideration elsewhere; 2 ) none of the paper's contents have been previously published; 3 ) they have read and approved the manuscript; 4) they have fully disclosed any relationship with industry; and 5) this study is partially supported by Samsung Biomedical Research Institute Grant (SBRI C-B1-114-1.6). All authors have declared any potential conflicts of interest. ES and CDB contributed equally to the hypothesis and wrote the manuscript. ES and CDB analysed data. ALW, LB, SPH, KGMC, $\mathrm{GCB}, \mathrm{KAL}, \mathrm{GFC}$ and PCC reviewed/edited the manuscript and contributed to discussion. CDB is the guarantor for the article.

Abbreviations: $\mathrm{Cl}$, confidence interval; $\mathrm{DHA}$, docosahexaenoic acid; EPA, eicosapentaenoic acid; HA, hyaluronic acid; MetS, metabolic syndrome; MRI, magnetic resonance imaging; MRS, magnetic resonance spectroscopy; NAFLD, non-alcoholic fatty liver disease; NASH, nonalcoholic steatohepatitis; PIINP, procollagen-III N terminal propeptide; PNPLA3, patatinlike phospholipase domain-containing protein-3; SD, standard deviation; TG, triglyceride; TM6SF2, transmembrane 6 superfamily member 2 protein (E167K). 
Clinical trial number: www.clinicalTrials.gov registration number NCT00760513. The WELCOME study was approved by the Southampton and South West Hampshire local research ethics committee (08/H0502/165).

Supported by: National Institute for Health Research Southampton Biomedical Research Unit in Nutrition (and Lifestyle) and Diabetes UK

Conflicts of interest: All authors, except PC Calder, GC Burdge and KA Lillycrop, have nothing to disclose. Potential conflicts of interest: Dr Calder advises Pronova BioPharma, Aker Biomarine, Smartfish, Sancilio, Solutex, DSM and Vifor Pharma. Drs GC Burdge and KA Lillycrop have research project support from Nestle and Abbott Nutrition. 


\section{ABSTRACT}

Background and Aims: Genetic variation in both patatin-like phospholipase domain-containing protein-3 (PNPLA3) (I148M) and the transmembrane 6 superfamily member 2 protein (TM6SF2) (E167K) influences severity of liver disease, and serum triglyceride concentrations in non-alcoholic fatty liver disease (NAFLD), but whether either genotype influences the responses to treatments is uncertain.

Methods: 103 patients with NAFLD were randomised to omega-3 fatty acids (DHA+EPA) or placebo for 15-18 months in a double blind placebo-controlled trial. Erythrocyte enrichment with DHA and EPA was measured by gas-chromatography. PNPLA3 and TM6SF2 genotypes were measured by PCR technologies. Multivariable linear regression and analysis of covariance were undertaken to test the effect of genotypes on omega-3 fatty acid enrichment, end of study liver fat percentage and serum triglyceride concentrations. All models were adjusted for baseline measurements of each respective outcome.

Results: 55 men and 40 women (Genotypes PNPLA3 I148M, CC=41, CG=43, GG=11; TM6SF2 E167K $\mathrm{CC}=78, \mathrm{CT}+\mathrm{TT}=17$ participants) (mean $\pm \mathrm{SD}$ age, $51 \pm 11$ years) completed the trial. Adjusting for baseline measurement, measured covariates and confounders, PNPLA3 (I148M) GG genotype was independently associated with \% DHA enrichment (B coefficient $-1.02(95 \% \mathrm{Cl}-1.97,-0.07), \mathrm{p}=0.036)$ but not \% EPA enrichment ( $\mathrm{B}$ coefficient $-0.31(95 \% \mathrm{Cl}-1.38,0.75), \mathrm{p}=0.56)$. This genotype was also independently associated with end of study \% liver fat (B coefficient $9.5(95 \% \mathrm{Cl} 2.53,16.39)$, $p=0.008)$, but not end of study triglyceride concentration (B coefficient $-0.11(95 \% \mathrm{Cl}-0.64,0.42)$, $\mathrm{p}=0.68)$.

Conclusions: PNPLA3 (I148M) GG genotype influences the changes in liver fat and DHA tissue enrichment during the trial but not the change in serum triglyceride concentration. 


\section{INTRODUCTION}

Non-alcoholic fatty liver disease (NAFLD) is strongly associated with type 2 diabetes, metabolic syndrome (MetS) (1) and weight loss (2). Omega-3 polyunsaturated fatty acid (PUFA) treatment (3) and weight loss (4) can be effective in decreasing liver fat and also triglyceride concentrations. Recently in patients with NAFLD we have suggested that the omega-3 fatty acid docosahexaenoic acid (DHA, 22:6n-3) may be more effective that the omega-3 fatty acid eicosapentanoic acid (EPA; 20:5n-3) in decreasing liver fat (5). In this randomised placebo-controlled trial that tested the effects of high dose purified omega-3 fatty acids, we showed an association between high levels of erythrocyte DHA, but not EPA, enrichment and decreased liver fat. Similarly, and in support of our findings, others have shown a benefit of omega-3 fatty acids to decrease liver fat, both in adults (6) and in children (7) with NAFLD. Although these findings are all consistent with the results of a recent systematic review and meta-analysis showing a benefit of omega-3 fatty acid treatment on liver fat in NAFLD (8), a recent trial that used high doses of EPA only, failed to show an improvement in NAFLD histological score (9). The reason for this apparent discrepancy in findings between the effects of DHA and EPA in NAFLD is uncertain, but there is considerable evidence that EPA and DHA have different biological effects in man (10-13) (14).

In NAFLD, patients with the homozygous GG (I148M) gene variant of the patatin-like phospholipase domain-containing protein-3 (PNPLA3) have higher levels of liver fat accumulation $(15,16)$ and lower serum fasting TG concentration, compared to those without the homozygous gene variant (17). The precise mechanism by which variation in PNPLA3 genotype induces hepatic lipid accumulation and decreased fasting triglyceride concentration is not clear. With regard to regulation of liver lipid, PNPLA3 exhibits both 
acyltransferase activity and TG hydrolase activity (18). The PNPLA3 I148M GG genotype has been shown to reduce secretion of large TG-rich VLDL particles in obese men with hepatic steatosis and to impair apoB100 secretion (19). Moreover, the PNPLA3 I148M GG genotype is known to facilitate the differential incorporation into liver lipid droplets of different types of fatty acid, for example vaccenic and palmitoleic acids, thereby altering the fatty acid composition of the lipid droplets (20). Recent data suggest that in humans PNPLA3 I148M regulates the efflux and remodelling, but not the influx, of lipid into hepatic lipid droplets (17, 20-22). In mice, Peter et al. (23) have shown that PNPLA3I148M GG genotype is characterised by a decrease in lipolytic activity and lysophosphatidic acid acyl-CoA transferase activity, with a greater than twofold preference for PUFAs. These investigators also showed that there was a reduction of DHA in the hepatocytes of mice overexpressing PNPLA3 I148M GG genotype. Additionally, Ruhanen et al (20) have shown that fatty acid composition was altered in cells expressing PNPLA3 I148M GG genotype with an increase of 18:1 n-7 and 16:1 n-7 (vaccenic and palmitoleic acids, respectively).

Moreover, recent studies have also identified that genetic variation in the transmembrane 6 superfamily member 2 protein (TM6SF2) at rs58542926 influences NAFLD severity, and contributes to lower levels of fasting triglycerides $(24,25)$. Although genetic variation in both PNPLA3 and TM6SF2 is known to influence severity of liver disease, and fasting serum triglyceride concentrations in NAFLD, it is presently uncertain whether either genotype influences the responses to treatments for NAFLD. The aim of our study was to test whether either PNPLA3 (I148M) or TM6SF2 (E167K) genotypes affected: a) the level of DHA and EPA enrichment; b) end of study liver fat percentage and c) end of study fasting triglyceride concentration, in patients with NAFLD treated for 15-18 months with DHA+EPA. The present 
study was a sub-study of the randomised placebo-controlled WELCOME trial $(5,26)$ (Wessex

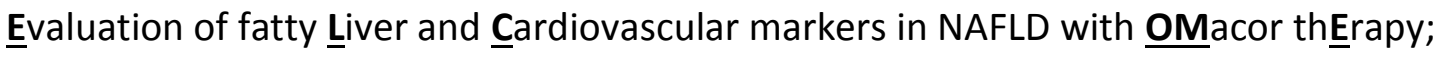
www.clinicalTrials.gov registration number NCT00760513) in which liver fat percentage and fasting serum triglyceride concentrations decreased due to DHA+EPA treatment and weight loss observed during the trial. 


\section{PATIENTS AND METHODS}

\section{Study design}

The WELCOME trial was a double blind placebo-controlled trial where we tested the effect of $4 \mathrm{~g}$ per day of Omacor ( $1 \mathrm{~g}$ of Omacor contains $460 \mathrm{mg}$ of EPA and $380 \mathrm{mg}$ of DHA as ethyl esters) or placebo for 15-18 months on liver-related primary outcomes in patients with NAFLD (26). Omacor, also known as Lovaza, was provided free of charge by Pronova BioPharma/Abbott (Pronova BioPharma ASA, Lysaker, Norway; Abbott Laboratories, Southampton, UK).

\section{Subjects and measurements}

We randomised 103 participants to either DHA+EPA $(n=51)$ or placebo $(n=52)$ and 95 participants completed the study $(\mathrm{DHA}+\mathrm{EPA}=47$; placebo=48). Consort diagram and the baseline characteristics of both placebo and active groups have been reported previously (5). All participants had NAFLD and features of metabolic syndrome. Metabolic syndrome was defined using the International Diabetes Federation criteria (27), the criteria for defining NAFLD were reported previously (26). Blood pressure was measured using a Marquette Dash 3000 monitor (GE Healthcare, Little Chalfont, Bucks, UK) in the nondominant arm. Waist circumference was measured over bare skin, midway between the costal margin and the iliac crest. Hip circumference was measured at the widest part between the greater trochanter and lower buttock level. Radiological assessments of body fat (dual-energy X-ray absorptiometry, DEXA) were undertaken at both baseline and end of study. DEXA scanning was undertaken with a Delphi W instrument (Hologic, Bedford, MA, USA) to assess percentage body fat, fat distribution and lean mass. Glucose, insulin, total cholesterol, HDL-cholesterol, TG, alanine aminotransferase (ALT) and aspartate aminotransferase (AST) and cytokeratin-18 (CK-18 M65 as a marker of liver apoptosis (28)) 
were measured in fasting serum. For measurement of serum TG concentration, the intraassay coefficient of variation (CV) was $1 \%$ and the inter-assay CV was $1.7 \%$, for TG concentrations $<88.5 \mathrm{mg} / \mathrm{dL}$. Magnetic resonance imaging (MRI) of abdominal visceral and subcutaneous fat and MR spectroscopy of hepatic lipid content were undertaken at the beginning and at the end of the study. Any change in diet during the study was assessed by food frequency questionnaire and we also generated a 'prudent diet score' as a healthy diet index, using principal component analyses (29). Drug medication was recorded at each study visit. At 6 months, 12 months and end of study, participants returned all used study capsules. Returned capsules were counted to assess compliance to allocated DHA+EPA or placebo.

\section{DHA and EPA enrichment in erythrocytes}

We measured DHA and EPA in erythrocytes at the beginning and at the end of the treatment by gas chromatography $(30,31)$. Enrichment was defined as the difference between end of study and baseline measurements. Total lipids were extracted from thawed packed erythrocytes $(300 \mu \mathrm{l})$ with $5 \mathrm{ml}$ chloroform:methanol $(2: 1 \mathrm{v} / \mathrm{v})$ containing butylated hydroxytoluene (50 mg/L) (32). Fatty acid methyl esters (FAMEs) were synthesised by heating the total lipid extract with $1 \mathrm{ml}$ methanol containing $2 \%$ (vol/vol) $\mathrm{H}_{2} \mathrm{SO}_{4}$ at $50^{\circ} \mathrm{C}$ for 2 h (30), FAMEs were extracted with hexane and analysed using a Hewlett Packard 6890 gas chromatograph fitted with a BPX-70 fused silica capillary column (30 $\mathrm{m} \times 0.22 \mathrm{~mm} \times 0.25$ $\mu \mathrm{m})$ with flame ionisation detection (30). FAMEs were identified by comparison of retention times with those of authentic standards. Intra-assay CVs for EPA and DHA were 3.0\% and 2.0\% respectively. Inter-assay CVs for EPA and DHA were $5.0 \%$ and $2.2 \%$ respectively. 


\section{DNA analyses}

Blood was collected from participants at baseline for determination of polymorphisms in the gene encoding PNPLA3. DNA was extracted from $200 \mu \mathrm{l}$ whole blood using QIAamp blood DNA blood mini kit (Qiagen, 51106), as per manufacturer's instructions. All samples were eluted in $200 \mu \mathrm{l}$ DNAse free water. Quality and quantity of DNA was confirmed by spectrophotometry using a Nanodrop 2000 (Thermo Scientific), where all samples had a 260/280 ratio $\geq 1.8$. PCR primers (Table. 1 ) were designed using PyroMark Assay Design 2.0 software (Biotage) to investigate the SNP rs738409 in the human PNPLA3-I148M gene variant. PCR was carried out on 25 ng DNA using $25 \mu$ KAPA2G Robust Hot Start Taq (Anachem, KK5702) and 0.2 $\mu \mathrm{M}$ of forward (5' AGCAGAGAAAGCCGACTTACCAC 3') and reverse (5' GGGTGCTCTCGCCTATAACTTC 3') primers in a $50 \mu$ l reaction. PCR products were immobilised on streptavidin-sepharose beads (GE Healthcare UK Ltd., 17-5113-01), washed, denatured and released into annealing buffer containing the sequencing primer $\left(5^{\prime}\right.$ ATGTTCCTGCTTCAT 3'). PNPLA3 SNP genotype was analysed using Pyromark ND 1.0 Software (Biotage). TM6SF2 genotype was determined using TaqMan C_89463510_10 Genotyping assay (Life technologies 4351379) and TaqMan Genotyping Master Mix (Life Technologies, 4371353) and analysed using LightCycler 480 SW 1.5.1 software (Roche). The rs58542926 C>T (E167K, TM6SF2) single-nucleotide polymorphisms were assessed in duplicate. Analytical pass rate was $100 \%$.

\section{Statistical analyses}

All statistical analyses were performed using SPSS for Windows (version 21.0; SPSS). We examined baseline and end of study characteristics in DHA+EPA and placebo groups. Data are reported as means and $95 \% \mathrm{Cls}$ or SDs for normally distributed variables, or as median 
and interquartile range (IQR), or ranges with maxima and minima for non-normally distributed variables. Comparisons of means between groups were performed by using ttests for normally distributed variables and Mann Whitney $U$ for non-normally distributed unpaired variables. Comparisons of paired data were tested by paired t tests, Wilcoxon signed rank and McNemar's tests. Multivariable linear regression modelling with backwards elimination was undertaken to test independent associations with these outcome variables: a) end of study TG concentration, b) end of study liver fat $\%$ c) DHA or EPA percentage enrichment in erythrocytes (end of study \% minus baseline \%). In each of these separate regression models, we adjusted for the baseline measurement of the outcome measure in question. Covariates, potential confounders and change in potential confounders between baseline and end of study were included, to test the independence of associations between key exposures and the outcome in question. Explanatory variables that were included in the models were continuous or categorical. For PNPLA3 and TM6SF2 genotype, a binary indicator variable was created and coded as $C G+C C=0$ and $G G=1$, or $C C=0$ and $C T+T T=1$ respectively. Differences between variables in PNPLA3 genotype groups and in TG quartile groups were tested by ANOVA or Kruskal Wallis depending on whether variables were normally or non-normally distributed. A P value of $<0.05$ was considered to be statistically significant. ANCOVA analyses were also undertaken test the effects of allelic variation of the genotypes for PNPLA3 and TM6SF2 on the study outcomes and to estimate the adjusted mean differences, according to genotype, between baseline and end of study in the study outcomes. Each ANCOVA model was adjusted for the same potential confounders as shown in the linear regression models. 


\section{RESULTS}

\section{Subject characteristics}

Table 1 shows the baseline and end-of-study results for the main anthropometric and biochemical variables, according to randomization group. Ninety-five participants completed the study ( 55 men and 40 women) and 32 of these had diabetes. At baseline, fasting TG concentration and BMI were higher in the DHA+EPA group compared with the placebo group ( $p=0.04$ and $p=0.02$, respectively). At baseline, there were no differences between the groups in MRI visceral fat measurements, waist circumference and weight. At baseline, $7.4 \%(n=7)$ of participants were taking fibrates, $6.3 \%(n=6)$ were taking ezetimibe, 44.2\% ( $n=42)$ were taking statins, $4.2 \%(n=4)$ were taking orlistat and $9.5 \%(n=9)$ were taking Levothyroxine. At the end of the study, there were $9.5 \%(n=9)$ of people taking fibrates, $5.3 \%(n=6)$ people were taking ezetimibe, $49.5 \%(n=47)$ people taking statins, $1.1 \%(n=1)$ were taking orlistat (Table 1), 10.5\% ( $n=10)$ were taking Levothyroxine. With regard to other metabolic and biochemical variables, there were no significant differences between randomisation groups (Table 1). Diet (assessed by prudent diet score) and alcohol intake did not change significantly during the study in either group. Capsule count at 6 months, 12 months and at end of study confirmed that compliance with treatment was at least $78 \%$ of all allocated capsules in all participants during the duration of the study. No serious adverse events occurred that were attributed to DHA+EPA or placebo.

Table 1 also shows fatty acid percentages in erythrocytes at baseline and at the end of study in the placebo and DHA+EPA groups. Despite very good compliance with the DHA+EPA intervention in the treatment arm, there was very variable DHA and EPA enrichment between individuals. Some individuals had only limited enrichment of either fatty acid while others had excellent enrichment, which did not relate to numbers of capsules consumed. 
For example, for DHA and EPA, the range of change in concentrations in erythrocyte membranes was from $-1.8 \%$ to $+5.6 \%$ (DHA) and from $-0.9 \%$ to $+6.2 \%$ (EPA). In the placebo group, there was no change in enrichment in EPA and there was a very small increase in DHA enrichment.

In our cohort, at baseline 42 participants had the PNPLA3 (I148M) CC genotype, 43 had the CG genotype and 13 had the GG genotype. Table 2 describes the baseline characteristics of the cohort stratified by PNPLA3 genotype. There were between group differences for DHA \% $(p=0.03)$. With regard to TM6SF2 (E167K) genotype, 80 participants had the CC genotype, 15 had the CT genotype and 3 had the TT genotype (Table 3 ).

The effects of PNPLA3 (I148M) and TM6SF2 (E167K) genotypes on DHA and EPA enrichment

We then tested whether PNPLA3 (I148M) GG genotype was independently associated with either erythrocyte DHA or EPA \% enrichment between baseline and end of study. For DHA enrichment, the multivariable linear regression model included \% change in erythrocyte DHA enrichment (end of study - baseline \% enrichment) as the outcome, and age, sex, baseline liver fat \%, PNPLA3 (I148M) GG genotype, TM6SF2 genotype CT+TT, BMI, diabetes, \% DHA enrichment at baseline, total fat mass, change in CK-18 M65 (between end of study and baseline), triglyceride concentration at baseline, use of orlistat, $L$ thyroxine, fibrates, beta blockers, and thiazide diuretics at baseline and capsule count. In this model, PNPLA3 (I148M) GG was independently associated with \% DHA enrichment (unstandardized B coefficient enrichment $-1.02(95 \% \mathrm{Cl}-1.97,-0.07), \mathrm{p}=0.036)$. In contrast, when this regression model was adjusted to test associations between PNPLA3 (I148M) GG genotype and \% EPA 
enrichment, there was no significant association (unstandardized B coefficient $-0.31(95 \% \mathrm{Cl}$ $-1.38,0.75), p=0.56)$. TM6SF2 genotype was not independently associated with either EPA or DHA enrichment.

\section{Effect of PNPLA3 and TM6SF2 genotypes on end of study liver fat percentage and end of}

\section{study triglyceride concentration}

Between baseline and end of study the change in liver fat \% was -7.0 (14) (median and IQR) in the PNPLA3 $(C C+C G)$ genotype groups compared with $+1.2(9.0)$ (median and IQR) in the GG group ( $p=0.027$ ). The change in liver fat was $-4 \%(20)$ (median and IQR) in the TMS6SF2 CC genotype and in the TMS6SF2 CT+TT genotype it was 0.75 (12.3) (median and IQR). Between baseline and end of study the change in serum triglyceride concentration was (median and IQR) $-0.1(0.8)$ in the PNPLA3 $(C C+C G)$ genotype groups compared with +0.3 (0.9) in the GG group ( $p=0.22)$. In presence of the TMS6SF2 CC genotype the changes in triglycerides were $-0.1 \mathrm{mmol} / \mathrm{L}(0.8)$ (median and IQR) and $-0.1 \mathrm{mmol} / \mathrm{L}(0.6)$ (median and IQR) in the TMS6SF2 CT+TT genotype group respectively.

The effect of PNPLA3 (I148M) GG genotype on end of study liver fat percentage and end of study triglyceride concentration was then investigated adjusting for covariates and potential confounders. From the results of univariate analyses (data not shown), for liver fat \%, factors included in the regression modelling included age, sex, baseline liver fat \%, PNPLA3 genotype, TM6SF2 genotype CT+TT, BMI, diabetes, \% DHA enrichment (end of study \% baseline \% DHA), baseline serum triglyceride, total fat mass, change in M65 (between end of study and baseline), use of orlistat at baseline, use of $L$ thyroxine at baseline and capsule count. Table 4 shows the only factors that were independently associated with end of study 
liver fat \%. DHA enrichment and decrease in weight $(\mathrm{kg})$ during the 15-18 months of the trial, were both independently associated with end of study \% liver fat and baseline \% liver fat was also independently associated with end of study \% liver fat. Additionally, PNPLA3 (I148M) GG genotype was independently associated with end of study \% liver fat (B coefficient B coefficient $9.5(95 \% \mathrm{Cl} 2.53,16.39), p=0.008)$. Overall this model (Table 4) accounted for $54 \%$ of the variance in end of study \% liver fat $\left(R^{2}=0.54, p<0.0001\right)$.

The effect of PNPLA3 (I148M) GG genotype on end of study triglyceride concentration was then investigated. From the results of univariate analyses (data not shown), factors included in the model, were age, sex, baseline liver fat \%, MRS difference, PNPLA3 genotype, TM6SF2 genotype $\mathrm{CT}+\mathrm{TT}$, BMI, diabetes, \% EPA enrichment (end of study - baseline \% enrichment), total fat mass, change in M65 (between end of study and baseline), triglyceride concentration at baseline, and use of orlistat, $L$ thyroxine, fibrates, beta blockers, and thiazide diuretics at baseline, and capsule count. Factors that were independently associated with end of study triglyceride concentrations are shown in Table 5. In contrast to the data for end of study \% liver fat, PNPLA3 genotype GG (I148M) was not associated with end of study triglyceride concentration (B coefficient $-0.11(95 \% \mathrm{Cl}-0.64,0.42), \mathrm{p}=0.68)$. Additionally, \% EPA enrichment (B coefficient $-0.19(95 \% \mathrm{Cl}-0.31,-0.07), \mathrm{p}=0.002)$ and not $\%$ DHA enrichment was independently associated with end of study triglyceride concentration. Factors included in the regression model shown in Table 5 explained $56 \%$ of the variance in end of study triglyceride concentration $\left(R^{2}=0.56, p<0.0001\right)$. We did not find any relationship between TMS6SF2 genotype and MRS liver fat or fasting triglyceride concentrations. However, we observed a significant difference in fasting TG at baseline by genotype; for the TMS6SF2 CT+TT genotype, triglycerides at baseline were lower (1.5 
$\mathrm{mmol} / \mathrm{L}(0.7)$ (median and IQR)) than for the TMS6SF2 CC genotype (1.8 $\mathrm{mmol} / \mathrm{L}(1.4)$ (median and IQR)) ( $p=0.02)$.

Since the evidence suggests that PNPLA3 (I148M) G/G genotype influences hepatic fat accumulation and liver damage with an additive effect of each $\mathrm{G}$ allele $(33,34)$, we tested the additive effective of allelic variation for PNPLA3 (I148M) genotype on change in liver fat percentage and change in fasting serum triglyceride between baseline and end of study. Each ANCOVA model (Table 6) was adjusted for the same potential confounders as shown in Tables 4 and 5. These data show that although there was a change in liver fat $\%$ between baseline and end of study in each PNPLA3 genotype the adjusted mean difference in liver fat \% was greater for PNPLA3 I148I C/C and for PNPLA3 I148IM C/G (with a decrease in liver fat $\%$ between baseline and end of study), compared with the PNPLA3 I148M G/G group where there was a small increase in liver fat \%. For change in triglyceride concentration between baseline and end of study, there was no significant effect of PNPLA3 genotype (in keeping with the results of regression modelling presented in Table 5). 


\section{DISCUSSION}

The novel results of our study are that in patients with NAFLD, the PNPLA3 (I148M) GG genotype, and not either the TM6SF2 (E167K) CT+TT or CC genotypes, was associated with markedly higher end of study liver fat percentage and lower DHA tissue enrichment (after 4 g DHA+EPA intervention for 15-18 months). In contrast, neither PNPLA3 (I148M), nor TM6SF2 (E167K) genotypes were associated with end of study serum triglyceride concentrations. As can be seen in Table 4, after adjusting for baseline \% liver fat, baseline body fat mass, and other covariates and confounders, the key independent factors associated with end of study liver fat \%, were a decrease in weight during the trial, baseline body fat, an increase in tissue \% DHA enrichment, PNPLA3 (I148M) GG genotype, and baseline liver fat \%. Differences between baseline and end of study of participant characteristics, according to PNPLA3 (I148M) genotype are shown in the Supplementary Table.

Previously, the strength of effect of the PNPLA3 (I148M) GG genotype on liver fat has been assessed in a meta-analysis of 16 studies (2,937 subjects) across different populations with NAFLD. In this analysis, PNPLA3 (I148M) GG genotype was associated with $73 \%$ higher liver fat content compared with the CC variant (33). In keeping with this evidence, in our subjects at baseline, median liver fat percentage was $28.5 \%$ in subjects with PNPLA3 (I148M) GG compared with $22.6 \%$ in subjects with CC or CG. However, to date it is uncertain how PNPLA3 (I148M) GG genotype modifies any response to treatment interventions in NAFLD. Very recently it has been suggested that there was a greater reduction in \% liver fat with a 12 month lifestyle intervention in subjects with the PNPLA3 (I148M) GG genotype (35) than in subjects with CG or CC genotype. However, initial baseline mean \% liver fat in the 
intervention group was surprisingly low (i.e. 5.5\%) and was only $4.3 \%$ in the PNPLA3 (I148M) GG group. As can be seen from our results and from the unstandardized B coefficient in Table 4, even after adjusting for baseline liver fat \%, PNPLA3 (I148M) GG genotype was associated with $10 \%$ higher end of study liver fat than seen in subjects with either PNPLA3 CC or CG. Importantly, this effect of PNPLA3 (I148M) GG genotype was independent of any benefit conferred by decrease in body weight and increased \%DHA enrichment (Table 4). DHA+EPA treatment produced highly variable inter-individual DHA and EPA tissue enrichment, and importantly this enrichment was independent of compliance and the numbers of capsules returned unused during the trial. PNPLA3 (I148M) GG was associated with decreased DHA enrichment but was not associated with EPA enrichment. It is known that omega-3 fatty acids are rapidly incorporated into plasma membranes where they affect membrane fluidity and membrane permeability (36) and that measurement of erythrocyte DHA and EPA enrichment is considered a good proxy for omega-3 fatty acid enrichment and bioavailability in liver (37). However, based on our results, PNPLA3 I148M is involved in DHA/EPA mobilization in liver and subjects with PNPLA3 (I148M) GG genotype have lower levels of DHA (38). Additionally, omega-3 fatty acids decrease the expression of sterol response element binding protein 1c (SREBP1c), a key regulatory factor in hepatic lipogenesis (39), and recently it has been shown that carriers of the PNPLA3 148M allele have decreased de novo lipogenesis (22). Thus, it is possible that the lack of response to DHA+EPA treatment in decreasing liver fat \% in subjects with PNPLA3 I148 MM could be due to the fact that these subjects already have low levels of de novo lipogenesis. That said, it is not known whether PNPLA3 (I148M) GG genotype affects the incorporation of DHA (or EPA) into the liver lipid droplet, although recent evidence in a small study in children suggests that the PNPLA3 (I148M) GG genotype attenuates the benefit of DHA to decrease liver fat 
(40). These data in children are in agreement with, and are extended by, our data, showing PNPLA3 (I148M) GG genotype is associated with lower levels of DHA enrichment. We show for the first time that the PNPLA3 (I148M) GG genotype is associated with a 1 SD decrease (i.e. a 1.2\% decrease) in erythrocyte DHA enrichment (unstandardized B coefficient -1.02 $(95 \% \mathrm{Cl}-1.97,-0.07), \mathrm{p}=0.036)$. A 1 SD decrease in \% DHA enrichment means that most individuals with the PNPLA3 GG genotype do not achieve the $2 \%$ DHA enrichment threshold that we have shown was necessary to achieve satisfactory reductions in liver fat in this cohort (5). Since our data show that higher levels of \% DHA enrichment are associated with lower levels of liver fat (5), it is noteworthy that most patients with PNPLA3 (I148M) GG genotype do not achieve high levels of \% DHA enrichment. Similarly, others have shown an effect of PNPLA3 genotype to modify treatment effect and a recent research study by Dongiovanni et al. (41) has shown that statin treatment was associated with a reduction in liver fat content and inflammation in individuals with NAFLD, carrying the PNPLA3 (I148I) CC genotype. The effect was absent in those with the PNPLA3 (I148I) GG genotype.

The mechanism by which PNPLA3 (I148M) GG genotype affects fasting TG concentration is uncertain. Hyysalo et al. showed in non-obese people with NAFLD that the PNPLA3 (I148M) GG genotype is associated with hepatic hydrolysis of TG, reducing hepatic VLDL secretion (17) but it is uncertain whether PNPLA3 (I148M) GG genotype modifies any change in triglyceride concentrations induced by an intervention. $4 \mathrm{~g}$ of DHA+EPA (as Omacor or Lovaza) contains similar amounts of DHA (1520 mg) and EPA (1840 mg) as ethyl esters and our data suggest that a greater TG-lowering effect was associated with EPA enrichment rather than DHA enrichment. Our data (Table 4) show the factors that were associated with end of study fasting serum triglyceride concentrations (adjusting for baseline measurement and other confounders and covariates). These data show that many factors (but not PNPLA3 
or TM6SF2 genotypes) were independently associated with triglyceride concentrations and, as expected, capsule count was independently associated with end of study triglyceride concentration. This finding is also consistent with licensing data for Omacor for the treatment for high serum triglyceride concentrations, where $4 \mathrm{~g}$ per day is the highest licenced dose, and $4 \mathrm{~g}$ is more effective in lowering serum triglyceride concentrations than 2 to $3 \mathrm{~g} /$ day. It is possible that PNPLA3 (I148M) genotype only influences VLDL secretion (and thereby fasting triglyceride concentrations), when there are specific hepatic lipids available for incorporation into the secreted VLDL particle (42). Thus, it is plausible that PNPLA3 (I148M) genotype may have little or no effect on VLDL levels when there is a modification in the quality of fatty acids and the type of hepatic lipid content (20) (e.g. as may occur after DHA treatment).

Our study has strengths but also some limitations. The main limitation is the small sample size. However this study is the first study to test the effects of the PNPLA3 (I148M) and TM6SF2 (E167K) genotypes on relevant end points in NAFLD as part of an intervention trial testing the effects of high dose DHA+EPA treatment in adults. This study was a sub-study of the main trial whose primary end point was to test improvements in liver disease per se, rather than changes in fasting TG. We have presented data showing the effects of genotypes on change in \% liver fat and change in serum triglyceride in NAFLD, rather than test the effect of genotypes on change in liver fibrosis biomarkers or other biomarkers of NAFLD severity that are known to be affected by PNPLA3 (I148M) and TM6SF2. The reason for this (as reported previously) was that these measures did not change between baseline and end of study during the trial (5). The sample size calculation for the trial has been reported previously (26) and was based on change in liver fat \% and not changes in serum TG concentration. The strengths of our study are the randomised double blind placebo- 
controlled trial design that also included very detailed phenotyping of the patient cohort that enabled measurement of many potential confounders and a precise, quantitative measurement of \% liver fat at baseline and at the end of study.

In conclusion, DHA enrichment and loss of weight during the randomised double blind placebo controlled trial both independently decreased end of study \% liver fat, adjusting for baseline \% liver fat and all other measured covariates and confounders. PNPLA3 (I148M) GG, but not TM6SF2 genotypes, was strongly and negatively associated with DHA tissue enrichment and was associated with markedly higher ( $10 \%)$ end of study liver fat levels. In contrast, end of study fasting triglyceride concentrations were strongly associated with \% EPA enrichment but not PNPLA3 (I148M) or TM6SF2 (E167K) genotypes. 


\section{Acknowledgements}

This work was supported by the National Institute of Health Research (NIHR) through the NIHR Southampton NIHR Biomedical Research Unit in Nutrition (and Lifestyle), by Diabetes UK, and by the Parnell Diabetes Trust.

CDB, PCC and ES are supported in part by the National Institute for Health Research Southampton Biomedical Research Centre. 
Table 1. Baseline and end of study biochemical and anthropometric characteristics

\begin{tabular}{|c|c|c|c|c|c|c|}
\hline & \multicolumn{3}{|c|}{ Placebo group } & \multicolumn{3}{|c|}{ DHA+EPA group } \\
\hline Variables & Baseline & End of study & $p$-value & Baseline & End of study & $p$-value \\
\hline Age (y) & $54.0(9.6)$ & $55.4(9.6)$ & $\mathrm{n} / \mathrm{a}$ & $48.6(11.1)$ & $50.1(11.1)$ & $\mathrm{n} / \mathrm{a}$ \\
\hline $\operatorname{Sex}(M / F)$ & $35 / 17$ & $32 / 16$ & $\mathrm{n} / \mathrm{a}$ & $25 / 26$ & $23 / 24$ & $\mathrm{n} / \mathrm{a}$ \\
\hline Weight (kg) & $94.5(15.8)$ & $90.4(16.3)$ & 0.76 & $96.5(17)$ & $94.1(13)$ & 0.38 \\
\hline BMI $\left(\mathrm{kg} / \mathrm{m}^{2}\right)$ & $32.4(4.5)$ & $30.8(4.5)$ & 0.74 & $34.0(5.8)$ & 33.4 (4.9) & 0.30 \\
\hline Prudent Diet Score* & $0.09(0.97)$ & $-0.07(0.9)$ & 0.46 & $-0.1(1.0)$ & $0.03(1.0)$ & 0.55 \\
\hline Alcohol intake (Units/week) & 6.3 & 6.8 & 0.88 & 2.3 & 2.2 & 0.67 \\
\hline Waist circumference $(\mathrm{cm})$ & $108.1(11.5)$ & $107.7(10.3)$ & 0.65 & $114.4(13.4)$ & $112.3(10.4)$ & 0.96 \\
\hline $\begin{array}{l}\text { Diastolic blood pressure } \\
\qquad(\mathrm{mmHg})\end{array}$ & $86.3(7.4)$ & $82.9(6.5)$ & 0.75 & $85.4(12.3)$ & $81.7(8.2)$ & 0.006 \\
\hline $\begin{array}{l}\text { Systolic blood pressure } \\
\text { (mmHg) }\end{array}$ & $137.7(15.1)$ & $133.9(11.3)$ & 0.13 & $138.2(17.4)$ & $133.3(13.7)$ & 0.004 \\
\hline $\begin{array}{l}\text { Fasting plasma glucose } \\
\qquad(\mathrm{mmol} / \mathrm{L})\end{array}$ & $6.2(2.0)$ & $6.7(3.0)$ & 0.07 & $6.2(1.2)$ & $6.1(2.0)$ & 0.77 \\
\hline $\begin{array}{l}\text { Fasting plasma insulin } \\
\qquad(\mu \text { Unit/ml })\end{array}$ & $11.7(11.2)$ & $10.2(9.3)$ & 0.68 & $12.3(7.1)$ & $13.9(6.4)$ & 0.18 \\
\hline HbA1c (\%) & $6.7(1.2)$ & $6.0(2.0)$ & 0.18 & $5.9(0.9)$ & $5.7(2.0)$ & 0.64 \\
\hline Serum triglycerides (mmol/L) & $1.5(0.5)$ & $1.8(0.6)$ & 0.05 & $1.8(0.7)$ & $1.5(1.2)$ & 0.018 \\
\hline Serum cholesterol (mmol/L) & $4.5(0.8)$ & $4.8(1)$ & 0.28 & $4.9(1.1)$ & $4.7(1.1)$ & 0.17 \\
\hline LDL-cholesterol (mmol/L) & $2.7(0.7)$ & $2.8(0.8)$ & 0.38 & $3.0(0.9)$ & $2.8(0.9)$ & 0.12 \\
\hline HDL-cholesterol (mmol/L) & $1.1(0.3)$ & $1.1(0.2)$ & 0.91 & $1.0(0.2)$ & $1.1(0.3)$ & $<0.0001$ \\
\hline ALT (IU/L) & $59.5(45)$ & $48.5(25)$ & 0.03 & $55.0(51)$ & $44.0(34)$ & 0.89 \\
\hline AST (IU/L) & $50.0(25)$ & $35.0(17)$ & 0.02 & $39.0(24)$ & $30.0(27)$ & 0.97 \\
\hline
\end{tabular}




\begin{tabular}{|c|c|c|c|c|c|c|}
\hline DEXA total fat mass (g) & $\begin{array}{l}33252 \\
(8734)\end{array}$ & $30822(8136)$ & 0.34 & $38128(10565)$ & $\begin{array}{c}35694 \\
(8061.6)\end{array}$ & 0.09 \\
\hline DEXA total lean mass (g) & $\begin{array}{c}59017 \\
(11344)\end{array}$ & $\begin{array}{c}56396 \\
(11237)\end{array}$ & 0.14 & $56353(11564)$ & $\begin{array}{c}56218 \\
(10799)\end{array}$ & 0.61 \\
\hline DEXA andro/gynoid (ratio) & $1.2(0.2)$ & $1.2(0.1)$ & 0.13 & $1.2(0.1)$ & $1.1(0.1)$ & 0.72 \\
\hline MRI subcutaneous fat (\%) & $30.4(9.7)$ & $28.8(9)$ & 0.43 & $35.4(10.5)$ & $32.0(9.6)$ & 0.47 \\
\hline MRI visceral fat (\%) & $16.7(4.7)$ & $16.5(5.4)$ & 0.36 & $15.2(5.1)$ & $15.9(4.7)$ & 0.67 \\
\hline MRS liver fat \% & $\begin{array}{c}21.7 \\
(13.7,32.3)\end{array}$ & $\begin{array}{c}19.7 \\
(11.3,28.0)\end{array}$ & 0.006 & $\begin{array}{c}23.0(12.0 \\
47.5)\end{array}$ & $\begin{array}{c}16.3(9.0 \\
30.7)\end{array}$ & 0.01 \\
\hline $\begin{array}{c}\text { Erythrocyte DHA (\%) } \\
\text { enrichment }\end{array}$ & $4.1(1.6)$ & $5.0(1)$ & 0.002 & $3.8(1.2)$ & $7.1(1.3)$ & $<0.0001$ \\
\hline $\begin{array}{c}\text { Erythrocyte EPA (\%) } \\
\text { enrichment }\end{array}$ & $0.9(0.4)$ & $1.0(0.2)$ & 0.17 & $0.8(0.3)$ & $2.4(1.8)$ & $<0.0001$ \\
\hline Fibrates $\mathbf{n}$ & 4 & 4 & 1.0 & 3 & 5 & 0.5 \\
\hline Statins $\mathbf{n}$ & 23 & 23 & 1.0 & 19 & 24 & 0.06 \\
\hline Ezetimibe $n$ & 5 & 3 & 0.5 & 1 & 2 & 1.0 \\
\hline
\end{tabular}

Variables that are normally distributed are expressed as mean (standard deviation (SD)). Variables that are non-normally distributed are expressed as median (inter-quartile range (IQR)).

*Prudent Diet Score (continuous variable derived from food frequency questionnaire, see (26) 
Table 2. Baseline characteristics according to PNPLA3 (I148M) genotype

\begin{tabular}{|c|c|c|c|c|}
\hline \multirow[b]{2}{*}{ Phenotypes } & \multicolumn{3}{|c|}{ Genotypes } & \multirow[b]{2}{*}{$\begin{array}{c}\text { P value } \\
\text { (difference } \\
\text { between } \\
\text { groups) }\end{array}$} \\
\hline & $\begin{array}{c}\mathrm{CC} \\
\mathrm{N}=42\end{array}$ & $\begin{array}{c}\text { CG } \\
N=43\end{array}$ & $\begin{array}{c}\text { GG } \\
\mathrm{N}=13\end{array}$ & \\
\hline Weight (kg) & $96.8(20.2)$ & $97.9(15.4)$ & $89.3(10.8)$ & 0.5 \\
\hline BMI (kg/m²) & $34.6(6.5)$ & $33.2(4.8)$ & 31.7 (4.5) & 0.2 \\
\hline $\begin{array}{l}\text { Fasting plasma glucose } \\
\qquad(\mathrm{mmol} / \mathrm{L})\end{array}$ & $5.3(1.9)$ & $5.5(1.2)$ & $5.4(2.0)$ & 0.3 \\
\hline HOMA-IR & $2.5(2.4)$ & $3.1(4.6)$ & $2.6(1.1)$ & 0.3 \\
\hline $\begin{array}{l}\text { Serum triglyceride } \\
\text { (mmol/L) }\end{array}$ & $1.6(1.2)$ & $1.7(0.9)$ & $1.4(0.3)$ & 0.4 \\
\hline $\begin{array}{l}\text { Serum cholesterol } \\
(\mathrm{mmol} / \mathrm{L})\end{array}$ & $4.9(0.9)$ & $4.6(1.1)$ & $4.6(0.7)$ & 0.3 \\
\hline $\begin{array}{l}\text { HDL-cholesterol } \\
\text { (mmol/L) }\end{array}$ & $1.1(0.4)$ & $1.1(0.3)$ & $1.1(0.3)$ & 0.9 \\
\hline $\begin{array}{l}\text { LDL-cholesterol } \\
\text { (mmol/L) }\end{array}$ & $3.0(0.9)$ & $2.7(0.9)$ & $2.9(0.7)$ & 0.5 \\
\hline ALT (IU/L) & $53(44)$ & $55(33)$ & $70(65)$ & 0.4 \\
\hline AST (IU/L) & $38(21)$ & $39(26)$ & $45(54)$ & 0.5 \\
\hline MRS liver fat \% & 26.7 (20.9) & 28.8 (19.9) & 33.5 (17.5) & 0.5 \\
\hline $\begin{array}{c}\text { Erythrocyte EPA (\%) } \\
\text { baseline }\end{array}$ & $0.8(0.3)$ & $0.9(0.4)$ & $0.7(0.3)$ & 0.1 \\
\hline $\begin{array}{l}\text { Erythrocyte DHA (\%) } \\
\text { baseline }\end{array}$ & $3.7(1.2)$ & $4.3(1.4)$ & $3.6(1.4)$ & 0.03 \\
\hline
\end{tabular}

Variables that are normally distributed are expressed as mean (standard deviation (SD)). Variables that are non-normally distributed are expressed as median (inter-quartile range (IQR)). (CC = 148II, C/G=148 IM, GG= 148MM). 
Table 3. Baseline characteristics according to TM6SF2 genotype

\begin{tabular}{|c|c|c|c|}
\hline \multirow[b]{2}{*}{ Phenotypes } & \multicolumn{2}{|c|}{ Genotypes } & \multirow[b]{2}{*}{$\begin{array}{c}\text { P value } \\
\text { (difference } \\
\text { between } \\
\text { groups) }\end{array}$} \\
\hline & CC & $\mathrm{CT}+\mathrm{TT}$ & \\
\hline Weight (kg) & $94.9(15.1)$ & 98.5 (20.9) & 0.5 \\
\hline BMI $\left(\mathrm{kg} / \mathrm{m}^{2}\right)$ & $32.6(4.5)$ & $35.4(8.1)$ & 0.05 \\
\hline $\begin{array}{l}\text { Fasting plasma glucose } \\
\text { (mmol/L) }\end{array}$ & $6.3(2.7)$ & $6.1(1.3)$ & 0.6 \\
\hline HOMA-IR & 2.7 (2.9) & $4.0(5.8)$ & 0.7 \\
\hline $\begin{array}{l}\text { Serum triglyceride } \\
(\mathrm{mmol} / \mathrm{L})\end{array}$ & $1.6(1.1)$ & $1.5(0.7)$ & 0.02 \\
\hline $\begin{array}{l}\text { Serum cholesterol } \\
\text { (mmol/L) }\end{array}$ & $4.7(1.0)$ & $4.5(0.9)$ & 0.1 \\
\hline $\begin{array}{l}\text { HDL-cholesterol } \\
\text { (mmol/L) }\end{array}$ & $1.0(0.4)$ & $1.0(0.3)$ & 0.6 \\
\hline $\begin{array}{l}\text { LDL-cholesterol } \\
\text { (mmol/L) }\end{array}$ & $2.8(1.0)$ & $2.8(0.6)$ & 0.3 \\
\hline ALT (IU/L) & $55.0(51)$ & $55.0(58)$ & 0.8 \\
\hline AST (IU/L) & $42.0(24)$ & $39.0(40)$ & 0.8 \\
\hline MRS liver fat \% & $28.5(20.3)$ & $29.0(19.1)$ & 0.9 \\
\hline $\begin{array}{c}\text { Erythrocyte EPA (\%) } \\
\text { baseline }\end{array}$ & $1.1(1.4)$ & $0.5(0.7)$ & 0.1 \\
\hline $\begin{array}{c}\text { Erythrocyte DHA (\%) } \\
\text { baseline }\end{array}$ & $4.0(1.4)$ & $4.1(0.8)$ & 0.6 \\
\hline
\end{tabular}

Variables that are normally distributed are expressed as mean (standard deviation (SD)). Variables that are non-normally distributed are expressed as median (inter-quartile range (IQR)). (CC = 148II, C/G=148 IM, GG= 148MM). 
Table 4. Factors independently associated with end of study liver fat percentage with DHA+EPA treatment

\begin{tabular}{|c|c|c|c|}
\hline Variables & $\begin{array}{c}\text { Unstandardised } \\
\text { B coefficient }\end{array}$ & 95\%Cl & $\boldsymbol{p}$-value \\
\hline Baseline liver fat (\%) & -0.39 & $-0.60,-0.28$ & $<0.0001$ \\
\hline Total body fat mass (kgs) & 0.58 & $0.09,1.07$ & 0.021 \\
\hline Change in body weight (kg) & 0.79 & $0.25,1.32$ & 0.004 \\
\hline PNPLA3 (I148M) genotype GG & 9.5 & $2.53,16.39$ & 0.008 \\
\hline \% DHA enrichment & -1.50 & $-2.82,-0.19$ & 0.025 \\
\hline
\end{tabular}

Factors included in the model, age, sex, baseline liver fat \%, PNPLA3 genotype, TMS6SF2 genotype, \% DHA enrichment (end of study - baseline \% enrichment), baseline serum triglyceride, total fat mass, change in M65 (between end of study and baseline), BMI, diabetes, change in weight, use of orlistat at baseline, use of $L$ thyroxine at baseline and capsule count. $R 2=0.54, p<0.0001$. 
Table 5. Factors independently associated with end of study fasting triglyceride concentration with DHA+EPA treatment

\begin{tabular}{|c|c|c|c|}
\hline Variables & $\begin{array}{c}\text { Unstandardised B } \\
\text { coefficient }\end{array}$ & $95 \% \mathrm{Cl}$ & $\boldsymbol{p}$-value \\
\hline Age (y) & -0.03 & $-0.05,-0.02$ & $<0.0001$ \\
\hline Being male & 0.54 & $0.13,0.97$ & 0.011 \\
\hline Baseline triglycerides (mmol/L) & -0.47 & $-0.60,-0.34$ & $<0.0001$ \\
\hline Total body fat mass (kg) & -0.03 & $-0.05,-0.01$ & 0.003 \\
\hline Capsule count & -0.24 & $-0.45,-0.03$ & 0.025 \\
\hline Use of beta blockers & 0.85 & $0.07,1.63$ & 0.034 \\
\hline \% EPA enrichment & -0.19 & $-0.31,-0.07$ & 0.002 \\
\hline
\end{tabular}

ors included in the model, age, sex, baseline liver fat \%, PNPLA3 genotype, TMS6SF2 genotype, \% EPA enrichment (end of study - baseline \% enrichment), BMI, total fat mass, diabetes, change in M65 (between end of study and baseline), change in weight, triglyceride concentration at baseline, and use of orlistat, $L$ thyroxine, fibrates, beta blockers, and thiazide diuretics at baseline and capsule count. (N.B. PNPLA3 genotype GG (I148M) (B coefficient $-0.02(95 \% \mathrm{Cl}-0.52,0.49, p=0.95)$. Final model $\left.R^{2}=0.56, p<0.0001\right)$. 
Table 6. Adjusted mean differences for change in liver fat percentage, change in serum fasting triglyceride concentration and change in DHA percentage enrichment with DHA+EPA treatment, according to PNPLA3 genotype

\begin{tabular}{|c|c|c|c|}
\hline \multirow{2}{*}{ Phenotypes } & $\mathbf{3}$ & Genotypes \\
\cline { 2 - 4 } & $\mathbf{N}=\mathbf{4 2}$ & $\mathbf{N}=\mathbf{4 3}$ & $\mathbf{N}=\mathbf{1 3}$ \\
\hline $\begin{array}{c}\text { Adjusted mean change in } \\
\text { liver fat \% (95\%Cl) }\end{array}$ & $-7.05(-10.77,-3.33)$ & $-7.30(-10.75,-3.85)$ & $2.75(-4.22,9.73)$ \\
\hline $\begin{array}{c}\text { *Adjusted mean change } \\
\text { in triglyceride (mmol/L) } \\
\text { (95\%Cl) }\end{array}$ & $-0.12(-0.41,1.62)$ & $-0.09(-0.36,0.17)$ & $-0.20(-0.71,0.31)$ \\
\hline $\begin{array}{c}\S \text { Adjusted mean change } \\
\text { in DHA (\%) (95\%Cl) }\end{array}$ & $1.84(1.27,2.41)$ & $2.06(1.52,2.60)$ & $0.75(-0.23,1.72)$ \\
\hline
\end{tabular}

Change in liver fat \%: ANCOVA model adjustments: age, sex, baseline liver fat \%, PNPLA3 genotype, TM6SF2, BMI, diabetes, \% DHA enrichment (end of study - baseline \% enrichment), baseline serum triglyceride, total fat mass, change in M65 (between end of study and baseline), change in weight, use of orlistat at baseline, use of $L$ thyroxine at baseline and capsule count.

Pairwise comparisons $C / C \vee G G, p=0.02$ and $C / G \vee G G ~ p=0.012$.

*Change in triglycerides: ANCOVA model adjustments: age, sex, baseline liver fat \%, PNPLA3 genotype, TM6SF2, BMI, diabetes, \% EPA enrichment (end of study - baseline \% enrichment), total fat mass, change in M65 (between end of study and baseline), change in weight, triglyceride concentration at baseline, and use of orlistat, $L$ thyroxine, fibrates, beta blockers, and thiazide diuretics at baseline and capsule count. Pairwise comparisons $\mathrm{C} / \mathrm{C} v$ GG, $p=0.8$ and $C / G$ v GG $p=0.71$

$\S$ Change in DHA \% enrichment: ANCOVA model adjustments: , age, sex, baseline liver fat \%, PNPLA3 genotype, TM6SF2, BMI, diabetes, \% DHA baseline, baseline serum triglyceride, total fat mass, change in M65 (between end of study and baseline), change in weight, use of orlistat at baseline, use of $L$ thyroxine at baseline and capsule count. Pairwise comparisons $C / C \vee G G, p=0.06$ and $C / G \vee G G p=0.023$ 
Supplementary Table: Differences between baseline and end of study of participant characteristics according to PNPLA3 genotype

\begin{tabular}{|c|c|c|c|c|c|c|c|c|}
\hline \multirow[b]{2}{*}{ Phenotypes } & \multicolumn{3}{|c|}{ Genotypes Placebo } & \multirow[b]{2}{*}{$\begin{array}{c}P \\
\text { value }\end{array}$} & \multicolumn{3}{|c|}{ Genotypes Active } & \multirow[b]{2}{*}{$\begin{array}{c}P \\
\text { value }\end{array}$} \\
\hline & CC & CG & GG & & CC & CG & GG & \\
\hline Age & 54 & 55 & 54 & 0.9 & 52 & 45 & 49 & 0.1 \\
\hline $\begin{array}{c}\text { Sex } \\
\text { (Male/Female) }\end{array}$ & $12 / 7$ & $14 / 6$ & $7 / 3$ & $\mathrm{n} / \mathrm{a}$ & $9 / 14$ & $13 / 10$ & $1 / 2$ & $\mathrm{n} / \mathrm{a}$ \\
\hline Diabetes (y/n) & $12 / 7$ & $15 / 5$ & $5 / 5$ & $\mathrm{n} / \mathrm{a}$ & $15 / 8$ & $15 / 8$ & $3 / 0$ & $\mathrm{n} / \mathrm{a}$ \\
\hline $\begin{array}{c}\text { Waist } \\
\text { circumference } \\
(\mathrm{cm})\end{array}$ & $\begin{array}{c}2.8 \\
(8.3)\end{array}$ & $\begin{array}{l}-1.8 \\
(4.4)\end{array}$ & $\begin{array}{c}0.4 \\
(4.0)\end{array}$ & 0.07 & $\begin{array}{l}-0.4 \\
(3.4)\end{array}$ & $\begin{array}{c}0.8 \\
(5.3)\end{array}$ & $\begin{array}{c}-5 \\
(2.1)\end{array}$ & 0.2 \\
\hline Weight (kg) & $\begin{array}{l}-2.0 \\
(4.0)\end{array}$ & $\begin{array}{c}1.6 \\
(4.6)\end{array}$ & $\begin{array}{l}-0.65 \\
(3.7)\end{array}$ & 0.03 & $\begin{array}{c}0.7 \\
(3.6)\end{array}$ & $\begin{array}{c}0.2 \\
(5.6)\end{array}$ & $\begin{array}{c}2.8 \\
(1.6)\end{array}$ & 0.7 \\
\hline BMI $\left(\mathrm{kg} / \mathrm{m}^{2}\right)$ & $\begin{array}{l}-0.6 \\
(1.4)\end{array}$ & $\begin{array}{c}0.5 \\
(1.6)\end{array}$ & $\begin{array}{l}-0.3 \\
(1.4)\end{array}$ & 0.04 & $\begin{array}{c}0.3 \\
(1.3)\end{array}$ & $\begin{array}{c}0.1 \\
(1.8)\end{array}$ & $\begin{array}{c}0.8 \\
(0.6)\end{array}$ & 0.8 \\
\hline $\begin{array}{c}\text { Serum } \\
\text { triglyceride } \\
(\mathrm{mmol} / \mathrm{L})\end{array}$ & $\begin{array}{c}0.0 \\
(0.6)\end{array}$ & $\begin{array}{c}0.2 \\
(1.2)\end{array}$ & $\begin{array}{c}0.3 \\
(0.8)\end{array}$ & 0.5 & $\begin{array}{l}-0.1 \\
(1.2)\end{array}$ & $\begin{array}{l}-0.3 \\
(1.0)\end{array}$ & $\begin{array}{l}0.0 \\
(\mathrm{n} / \mathrm{a})\end{array}$ & 0.6 \\
\hline ALT (IU/L) & $\begin{array}{l}-1.0 \\
(23)\end{array}$ & $\begin{array}{c}-3 \\
(21.7)\end{array}$ & $\begin{array}{c}-14 \\
(34.0)\end{array}$ & 0.4 & $\begin{array}{c}3.0 \\
(37.2 \\
)\end{array}$ & $\begin{array}{c}-3.0 \\
(20.0)\end{array}$ & $\begin{array}{l}3.0 \\
(n / a)\end{array}$ & 0.4 \\
\hline AST (IU/L) & $\begin{array}{l}-3.0 \\
(17)\end{array}$ & $\begin{array}{l}-1.0 \\
(10.7)\end{array}$ & $\begin{array}{l}-9.0 \\
(31.5)\end{array}$ & 0.3 & $\begin{array}{c}-0.5 \\
(20.7 \\
)\end{array}$ & $\begin{array}{c}1.0 \\
(14.0)\end{array}$ & $\begin{array}{l}-1.5 \\
(n / a)\end{array}$ & 0.8 \\
\hline $\begin{array}{c}\text { MRS liver fat } \\
\%\end{array}$ & $\begin{array}{l}-7.6 \\
(10)\end{array}$ & $\begin{array}{l}-3.7 \\
(7.6)\end{array}$ & $\begin{array}{l}-0.4 \\
(9.3)\end{array}$ & 0.1 & $\begin{array}{c}-6.3 \\
(15.2 \\
)\end{array}$ & $\begin{array}{l}-10.2 \\
(18.8)\end{array}$ & $\begin{array}{c}8.1 \\
(4.0)\end{array}$ & 0.3 \\
\hline $\begin{array}{l}\text { Erythrocyte } \\
\text { EPA (\%) }\end{array}$ & $\begin{array}{c}0.1 \\
(0.3)\end{array}$ & $\begin{array}{l}-0.04 \\
(0.3)\end{array}$ & $\begin{array}{c}0.1 \\
(0.3)\end{array}$ & 0.1 & $\begin{array}{c}1.9 \\
(1.4)\end{array}$ & $\begin{array}{c}2.1 \\
(1.3)\end{array}$ & $\begin{array}{c}1.0 \\
(0.3)\end{array}$ & 0.5 \\
\hline $\begin{array}{l}\text { Erythrocyte } \\
\text { DHA (\%) }\end{array}$ & $\begin{array}{c}3.6 \\
(1.4)\end{array}$ & $\begin{array}{c}4.7 \\
(1.4)\end{array}$ & $\begin{array}{c}3.8 \\
(1.4)\end{array}$ & 0.05 & $\begin{array}{l}3.8 \\
(0.9)\end{array}$ & $\begin{array}{c}4.1 \\
(1.5)\end{array}$ & $\begin{array}{c}3.1 \\
(1.0)\end{array}$ & 0.3 \\
\hline
\end{tabular}

Variables that are normally distributed are expressed as mean (standard deviation (SD)). Variables that are non-normally distributed are expressed as median (inter-quartile range (IQR)). (CC = 148II, C/G=148 IM, GG= $148 \mathrm{MM}) . P$ value (difference between groups) 
Reference List

(1) Targher G, Byrne CD. Clinical Review: Nonalcoholic fatty liver disease: a novel cardiometabolic risk factor for type 2 diabetes and its complications. J Clin Endocrinol Metab 2013 Feb;98(2):483-495.

(2) Marchesini G, Mazzotti A. NAFLD incidence and remission: only a matter of weight gain and weight loss? J Hepatol 2015 Jan;62(1):15-17.

(3) Chan DC, Watts GF, Mori TA, Barrett PH, Redgrave TG, Beilin LJ. Randomized controlled trial of the effect of n-3 fatty acid supplementation on the metabolism of apolipoprotein B-100 and chylomicron remnants in men with visceral obesity. Am J Clin Nutr 2003 Feb;77(2):300307.

(4) Nascimbeni F, Pais R, Bellentani S, Day CP, Ratziu V, Loria P, et al. From NAFLD in clinical practice to answers from guidelines. J Hepatol 2013 Oct;59(4):859-871.

(5) Scorletti E, Bhatia L, McCormick KG, Clough GF, Nash K, Hodson L, et al. Effects of purified eicosapentaenoic and docosahexaenoic acids in non-alcoholic fatty liver disease: Results from the *WELCOME study. Hepatology 2014 Jul 4.

(6) Argo CK, Patrie JT, Lackner C, Henry TD, de Lange EE, Weltman AL, et al. Effects of n-3 fish oil on metabolic and histological parameters in NASH: a double-blind, randomized, placebocontrolled trial. J Hepatol 2015 Jan;62(1):190-197.

(7) Nobili V, Bedogni G, Alisi A, Pietrobattista A, Rise P, Galli C, et al. Docosahexaenoic acid supplementation decreases liver fat content in children with non-alcoholic fatty liver disease: double-blind randomised controlled clinical trial. Arch Dis Child 2011 Apr;96(4):350353.

(8) Parker HM, Johnson NA, Burdon CA, Cohn JS, O'Connor HT, George J. Omega-3 supplementation and non-alcoholic fatty liver disease: a systematic review and metaanalysis. J Hepatol 2012 Apr;56(4):944-951.

(9) Sanyal AJ, Abdelmalek MF, Suzuki A, Cummings OW, Chojkier M. No significant effects of ethyl-eicosapentanoic acid on histologic features of nonalcoholic steatohepatitis in a phase 2 trial. Gastroenterology 2014 Aug;147(2):377-384.

(10) Mori TA, Woodman RJ. The independent effects of eicosapentaenoic acid and docosahexaenoic acid on cardiovascular risk factors in humans. Curr Opin Clin Nutr Metab Care 2006 Mar;9(2):95-104.

(11) Mori TA, Burke V, Puddey IB, Watts GF, O'Neal DN, Best JD, et al. Purified eicosapentaenoic and docosahexaenoic acids have differential effects on serum lipids and lipoproteins, LDL particle size, glucose, and insulin in mildly hyperlipidemic men. Am J Clin Nutr 2000 May;71(5):1085-1094. 
(12) Woodman RJ, Mori TA, Burke V, Puddey IB, Barden A, Watts GF, et al. Effects of purified eicosapentaenoic acid and docosahexaenoic acid on platelet, fibrinolytic and vascular function in hypertensive type 2 diabetic patients. Atherosclerosis 2003 Jan;166(1):85-93.

(13) Mesa MD, Buckley R, Minihane AM, Yaqoob P. Effects of oils rich in eicosapentaenoic and docosahexaenoic acids on the oxidizability and thrombogenicity of low-density lipoprotein. Atherosclerosis 2004 Aug;175(2):333-343.

(14) Leigh-Firbank EC, Minihane AM, Leake DS, Wright JW, Murphy MC, Griffin BA, et al. Eicosapentaenoic acid and docosahexaenoic acid from fish oils: differential associations with lipid responses. Br J Nutr 2002 May;87(5):435-445.

(15) Romeo S, Kozlitina J, Xing C, Pertsemlidis A, Cox D, Pennacchio LA, et al. Genetic variation in PNPLA3 confers susceptibility to nonalcoholic fatty liver disease. Nat Genet 2008 Dec;40(12):1461-1465.

(16) Mashek DG, Greenberg AS. Serum TAG analysis differentiates between genetic and obesityassociated NAFLD. Diabetes 2014 Jan;63(1):42-44.

(17) Hyysalo J, Gopalacharyulu P, Bian H, Hyotylainen T, Leivonen M, Jaser N, et al. Circulating triacylglycerol signatures in nonalcoholic fatty liver disease associated with the $1148 \mathrm{M}$ variant in PNPLA3 and with obesity. Diabetes 2014 Jan;63(1):312-322.

(18) Farrell GC. PNPLeAse get the fats right: does lipogenesis or lipolysis cause NASH? Hepatology 2010 Sep;52(3):818-821.

(19) Pirazzi C, Adiels M, Burza MA, Mancina RM, Levin M, Stahlman M, et al. Patatin-like phospholipase domain-containing 3 (PNPLA3) I148M (rs738409) affects hepatic VLDL secretion in humans and in vitro. J Hepatol 2012 Dec;57(6):1276-1282.

(20) Ruhanen H, Perttila J, Holtta-Vuori M, Zhou Y, Yki-Jarvinen H, Ikonen E, et al. PNPLA3 mediates hepatocyte triacylglycerol remodeling. J Lipid Res 2014 Apr;55(4):739-746.

(21) Pingitore P, Pirazzi C, Mancina RM, Motta BM, Indiveri C, Pujia A, et al. Recombinant PNPLA3 protein shows triglyceride hydrolase activity and its $1148 \mathrm{M}$ mutation results in loss of function. Biochim Biophys Acta 2014 Apr 4;1841(4):574-580.

(22) Mancina RM, Matikainen N, Maglio C, Soderlund S, Lundbom N, Hakkarainen A, et al. Paradoxical Dissociation Between Hepatic Fat Content and De Novo Lipogenesis Due to PNPLA3 Sequence Variant. J Clin Endocrinol Metab 2015 May;100(5):E821-E825.

(23) Peter A, Kovarova M, Nadalin S, Cermak T, Konigsrainer A, Machicao F, et al. PNPLA3 variant I148M is associated with altered hepatic lipid composition in humans. Diabetologia 2014 Oct;57(10):2103-2107.

(24) Kahali B, Liu YL, Daly AK, Day CP, Anstee QM, Speliotes EK. TM6SF2: catch-22 in the fight against nonalcoholic fatty liver disease and cardiovascular disease? Gastroenterology 2015 Apr;148(4):679-684.

(25) Dongiovanni P, Petta S, Maglio C, Fracanzani AL, Pipitone R, Mozzi E, et al. Transmembrane 6 superfamily member 2 gene variant disentangles nonalcoholic steatohepatitis from cardiovascular disease. Hepatology 2015 Feb;61(2):506-514. 
(26) Scorletti E, Bhatia L, McCormick KG, Clough GF, Nash K, Calder PC, et al. Design and rationale of the WELCOME trial: A randomised, placebo controlled study to test the efficacy of purified long chain omega-3 fatty treatment in non-alcoholic fatty liver disease. Contemp Clin Trials 2014 Feb 17.

(27) Alberti KG, Eckel RH, Grundy SM, Zimmet PZ, Cleeman JI, Donato KA, et al. Harmonizing the metabolic syndrome: a joint interim statement of the International Diabetes Federation Task Force on Epidemiology and Prevention; National Heart, Lung, and Blood Institute; American Heart Association; World Heart Federation; International Atherosclerosis Society; and International Association for the Study of Obesity. Circulation 2009 Oct 20;120(16):16401645.

(28) Cusi K, Chang Z, Harrison S, Lomonaco R, Bril F, Orsak B, et al. Limited value of plasma cytokeratin-18 as a biomarker for NASH and fibrosis in patients with non-alcoholic fatty liver disease. J Hepatol 2014 Jan;60(1):167-174.

(29) Robinson S, Syddall H, Jameson K, Batelaan S, Martin H, Dennison EM, et al. Current patterns of diet in community-dwelling older men and women: results from the Hertfordshire Cohort Study. Age Ageing 2009 Sep;38(5):594-599.

(30) Browning LM, Walker CG, Mander AP, West AL, Madden J, Gambell JM, et al. Incorporation of eicosapentaenoic and docosahexaenoic acids into lipid pools when given as supplements providing doses equivalent to typical intakes of oily fish. Am J Clin Nutr 2012 Oct;96(4):748758.

(31) Burdge GC, Wright P, Jones AE, Wootton SA. A method for separation of phosphatidylcholine, triacylglycerol, non-esterified fatty acids and cholesterol esters from plasma by solid-phase extraction. Br J Nutr 2000 Nov;84(5):781-787.

(32) FOLCH J, LEES M, SLOANE STANLEY GH. A simple method for the isolation and purification of total lipides from animal tissues. J Biol Chem 1957 May;226(1):497-509.

(33) Sookoian S, Pirola CJ. Meta-analysis of the influence of I148M variant of patatin-like phospholipase domain containing 3 gene (PNPLA3) on the susceptibility and histological severity of nonalcoholic fatty liver disease. Hepatology 2011 Jun;53(6):1883-1894.

(34) Dongiovanni P, Donati B, Fares R, Lombardi R, Mancina RM, Romeo S, et al. PNPLA3 I148M polymorphism and progressive liver disease. World J Gastroenterol 2013 Nov 7;19(41):69696978.

(35) Shen J, Wong GL, Chan HL, Chan RS, Chan HY, Chu WC, et al. PNPLA3 gene polymorphism and response to lifestyle modification in patients with nonalcoholic fatty liver disease. J Gastroenterol Hepatol 2015 Jan;30(1):139-146.

(36) Stillwell W, Wassall SR. Docosahexaenoic acid: membrane properties of a unique fatty acid. Chem Phys Lipids 2003 Nov;126(1):1-27.

(37) Tan ZS, Harris WS, Beiser AS, Au R, Himali JJ, Debette S, et al. Red blood cell omega-3 fatty acid levels and markers of accelerated brain aging. Neurology 2012 Feb 28;78(9):658-664.

(38) Santoro N, Savoye M, Kim G, Marotto K, Shaw MM, Pierpont B, et al. Hepatic fat accumulation is modulated by the interaction between the rs738409 variant in the PNPLA3 gene and the dietary omega6/omega3 PUFA intake. PLoS One 2012;7(5):e37827. 
(39) Wojcik C, Lohe K, Kuang C, Xiao Y, Jouni Z, Poels E. Modulation of adipocyte differentiation by omega-3 polyunsaturated fatty acids involves the ubiquitin-proteasome system. J Cell Mol Med 2014 Apr;18(4):590-599.

(40) Nobili V, Bedogni G, Donati B, Alisi A, Valenti L. The I148M variant of PNPLA3 reduces the response to docosahexaenoic acid in children with non-alcoholic fatty liver disease. J Med Food 2013 Oct;16(10):957-960.

(41) Dongiovanni P, Petta S, Mannisto V, Margherita MR, Pipitone R, Karja V, et al. Statin use and nonalcoholic steatohepatitis in at risk individuals. J Hepatol 2015 May 13.

(42) Palmer CN, Maglio C, Pirazzi C, Burza MA, Adiels M, Burch L, et al. Paradoxical lower serum triglyceride levels and higher type 2 diabetes mellitus susceptibility in obese individuals with the PNPLA3 148M variant. PLoS One 2012;7(6):e39362. 